\title{
Long-term foliar persistence and efficacy of spinosad against beet armyworm under greenhouse conditions
}

\author{
Erika L Sántis, Luis A Hernández, Ana M Martínez, Jesús Campos, \\ José I Figueroa, Philippe Lobit, Juan M Chavarrieta, Elisa Viñuela, \\ Guy Smagghe and Samuel Pineda
}

\begin{abstract}
BACKGROUND: The immediate lethality caused by spinosad has been widely studied on Spodoptera exigua (Hübner). However, long-term effects can also provide valuable information on insecticide toxic action. Here, the persistence of spinosad on Capsicum annuum L. foliage and the lethal and sublethal effects of greenhouse-aged foliar residues of this insecticide on third instars of S. exigua are reported.

RESULTS: Foliage was collected at 0, 3, 5, 10, 20, 30, 40 and 50 days after application, and spinosad residues were measured. Residues decreased over time according to first-order kinetics. The average rate constant and half-life of disappearance were $4.44 \times 10^{-3}$ and 156 days and $5.80 \times 10^{-3}$ and 120 days for 60 and $120 \mathrm{mg} \mathrm{L}^{-1}$ respectively. Larval mortality gradually decreased, corresponding to the residues, but was still appreciable ( 35 and $65 \%$ for 60 and $120 \mathrm{mg} \mathrm{L}^{-1}$ respectively) when the larvae were fed with foliage collected 50 days after treatment. Subsequently, pupal development was reduced and varied between 20 and $60 \%$ and between 21 and $41 \%$ for 60 and $120 \mathrm{mg} \mathrm{L}^{-1}$, respectively, in all ages of leaf residues that were bioassayed. At all time points, the consumption rate by the larvae was reduced between 62 and $84 \%$ for both concentrations that were bioassayed.

CONCLUSION: It is concluded that, under the present greenhouse conditions, the degradation of spinosad was slower than that reported by other authors in the field, and, because of that, its residues could cause lethal and sublethal effects to $S$. exigua larvae.
\end{abstract}

Keywords: foliar persistence; half-life; biological activity; spinosad residues; consumption rate

\section{INTRODUCTION}

The beet armyworm, Spodoptera exigua (Hübner) (Lepidoptera: Noctuidae), is one of the most destructive insect pests of sweet pepper, tomato, aubergine, courgette, melon and watermelon crops in greenhouses around the world. ${ }^{1-3}$ Although it is originally from south-eastern Asia, this insect is now a cosmopolitan pest that is particularly abundant in North and Central America, Africa, Australia, southern Asia and Europe. ${ }^{4,5}$ In commercial greenhouses, growers attempt to control S. exigua infestations by applying broad-spectrum insecticides singly or in cocktails at weekly intervals, ${ }^{3}$ but the control achieved is not completely successful because of the insect's high capacity to develop resistance towards the majority of conventional compounds. ${ }^{2,6-8}$ To date, all documented cases of spinosad resistance in this pest are in the field, which could be expected given its smallscale use in greenhouses compared with open-field crops. ${ }^{7,8}$ Therefore, scientists and growers are seeking alternative tools that are effective against this pest, safe to humans, environmental friendly and compatible with integrated pest management (IPM) practices. One promising control tactic against S. exigua larvae in greenhouse and field conditions is the use of biorational control agents, such as those based on naturally derived products (i.e. spinosad). 9

Spinosad is a bioinsecticide that is based on the fermentation product of the soil bacterium Saccharopolyspora spinosa Mertz and Yao. ${ }^{10}$ This compound has two unique modes of action: it acts primarily on the insect's nervous system at the nicotinic acetylcholine receptor, and it also exhibits activity at the GABA 
receptor. ${ }^{11,12}$ Spinosad has been registered in $>30$ countries for the control of Lepidoptera, Coleoptera, Diptera and Thysanoptera, ${ }^{13,14}$ and is considered to be environmentally safe because of its large margins of safety for mammals, birds, fish and many beneficial insects. ${ }^{15,16}$ In addition, in the European Union, spinosad was included in Annex II-B of Council Regulation 2092/1991 for organic agriculture in $2008 .^{17}$

In toxicology, the ability to predict the lethal effects of toxicants on crop infestation by the target pest is normally the principal objective. ${ }^{18}$ However, other long-term effects can be caused in subsequent instars of the treated insects, which can provide valuable information on insecticide toxic action. ${ }^{19,20}$ Under field conditions, it is known that spinosad is degraded over time, ${ }^{19,20}$ so that, after several days of application, larvae of different ages are likely to be present, feeding on little quantities of the compound, which can impair their performance.

Laboratory bioassays provide information on the inherent and relative toxicity of an insecticide, but it is the longevity of residues that informs growers about retreatment intervals. ${ }^{21}$ Therefore, for growers effectively to incorporate new insecticide technologies in S. exigua management programmes, information on their residual toxicity under greenhouse conditions is needed. This toxicity should be evaluated because it could have a strong impact on the population dynamics of this lepidopteran pest and could contribute to its management.

The objectives of this study were as follows: firstly, to evaluate the persistence of spinosad applied to pepper plants, Capsicum annuum L., under greenhouse conditions and its degradation kinetics; secondly, to determine the toxicity of greenhouse-aged foliar residues of this insecticide, as well as its consumption rate by third instars of S. exigua.

\section{MATERIALS AND METHODS}

\subsection{Insects and rearing}

Insects used in these tests came from a colony of S. exigua maintained for 21 generations in the Instituto de Investigaciones Agropecuarias y Forestales, Universidad Michoacana de San Nicolás de Hidalgo (IIAF-UMSNH) (Tarímbaro, Michoacán, Mexico), and the colony had no history of insecticide exposure. The larvae were reared on a semi-synthetic diet (Cotton Bollworm diet; Southland Products Inc., Lake Village, AR) in a controlled environmental chamber at $25 \pm 2{ }^{\circ} \mathrm{C}$ with $75 \pm 5 \% \mathrm{RH}$ and a $16: 8 \mathrm{~h}$ light: dark photoperiod until the prepupal stage. Adults were released into $50 \times 20 \mathrm{~cm}$ brown paper bags for mating and egg laying and supplied with a $15 \%(\mathrm{w} / \mathrm{v})$ honey solution made with distilled water. The paper bags were replaced every 2 days.

\subsection{Insecticide application and sampling}

Pepper seeds, C. annuum Cannon (Zeraim Gedera Seed Company, Gedera, Israel), were allowed to germinate in a humus-rich soil in individual $3 \mathrm{~cm}$ pots for 2 weeks. Fourteen days after sowing, the plants were transplanted individually to black plastic bags (20 cm diameter $\times 25 \mathrm{~cm}$ high) containing a mixture of coconut fibre, humus-rich soil and volcanic iron oxide gravel known as tezontle $(1: 1: 2)$. All plants were watered as necessary and fertilised once a week (approximately $0.1 \mathrm{~g}$ per plant, NPK 14-20-7 with micronutrients).

Pepper plants of $\sim 45 \mathrm{~cm}$ height with 20 or 23 fully expanded true leaves were treated with 60 or $120 \mathrm{mg} \mathrm{L}^{-1}$ of $\operatorname{Tracer}^{\mathrm{TM}}\left(480 \mathrm{~g} \mathrm{~L}^{-1}\right.$ of spinosad, suspension concentrate; Dow AgroSciences, Zamora,
Michoacán, Mexico) with the use of a handheld sprayer until runoff. These concentrations correspond to one-half of the maximum field recommended concentration (MFRC) and the full MFRC respectively. To enhance the wetting of the leaves, the surfactant sodium dodecyl sulfate was used at $0.01 \%(\mathrm{w} / \mathrm{v})$. Control plants were sprayed with distilled water plus surfactant at $0.01 \%$ only. Twenty-three plants were used for each concentration and control.

After treatment, plants were maintained in the central part of a ventilated greenhouse $\left(120 \mathrm{~m}^{2}\right.$ in area) located on the campus of IIAF-UMSNH. Global radiation and EAS-weighted UV radiation were measured, ${ }^{22}$ outside and inside the greenhouse, using a Davis Vantage Pro weather station. The average visible and UV radiation inside the greenhouse during the time of the experiment (12 April 2011 to 25 May 2011) were $18 \mathrm{MJ} \mathrm{m}^{-2} \mathrm{day}^{-1}\left(305 \mathrm{~W} \mathrm{~m}^{-2}\right)$ and $5.2 \mathrm{~kJ} \mathrm{~m}^{-2} \mathrm{day}^{-1}\left(0.06 \mathrm{~W} \mathrm{~m}^{-2}\right)$. The plastic cover was responsible for a 30 and $75 \%$ reduction in visible and UV radiation respectively. Temperature and humidity within the greenhouse fluctuated little during this period. On average, the daily maximum and minimum temperatures were 41 and $13^{\circ} \mathrm{C}$ respectively, while maximum and minimum relative humidity were 72 and $14 \%$ respectively.

Leaves were collected from each insecticide treatment group at $5 \mathrm{~h}$ (considered as 0 days after treatment) and 3, 5, 10, 20, 30, 40 and 50 days after application. At each time point, one leaf per plant on 15 plants chosen at random from the 23 plants of each treatment was picked from the middle section to ensure it had been treated. This sample was then divided evenly for use in residue analysis and toxicity bioassays using third instars of the beet armyworm, S. exigua. The age of these leaves was estimated between 20 and 50 days according to the average leaf emission rate. Leaves from the control treatment plants were harvested at the same time intervals as the insecticide-treated leaves and were used to determine control mortality in the spinosad toxicity bioassays. The collected leaves were transported immediately to the laboratory after sampling, and those to be used in residue extraction studies were frozen at $-20^{\circ} \mathrm{C}$.

\subsection{Residue extraction and analysis}

Spinosad residue extraction in samples was carried out in triplicate as previously described. ${ }^{20,23}$ For extraction, the method of Sharma et al. ${ }^{20}$ was used, with an extraction efficacy of $83 \%$. Frozen leaves $(3.6 \mathrm{~g})$ were chopped and then extracted with $25 \mathrm{~mL}$ of an extraction solution that consisted of acetonitrile + methanol + distilled water $(5.3+3.3+1.3$ by volume $)$ and incubated for 25 min with shaking. Next, the $25 \mathrm{~mL}$ extraction solutions were recovered in $50 \mathrm{~mL}$ Falcon tubes. The solvents were evaporated using a water bath at $55^{\circ} \mathrm{C}$ for $10 \mathrm{~h}$. The remaining extracts were frozen at $-80^{\circ} \mathrm{C}$ and dried by lyophilisation (FreeZone Benchtop Shell Freezers, Kansas City, MO) for $7 \mathrm{~h}$. Samples were redissolved in $2 \mathrm{~mL}$ of extraction solution (defined above) and filtered using polyvinylidene fluoride $0.2 \mu \mathrm{m}$ filters (Millipore ${ }^{\mathrm{MT}}$, Billerica, $\mathrm{MA}$ ).

Spinosad residue samples ( $25 \mu \mathrm{L}$ ) were analysed by using a $C_{18}$ reverse-phase high-performance liquid chromatography (HPLC) column (Microsorb-MV 100-5; Varian Inc., Santa Clara, CA) in an HPLC system (ProStar 240; Varian Inc., Santa Clara, CA) equipped with a photodiode array detector (PDA 355; Varian Inc.) operating at 200-600 nm. Spinosad residue quantification was performed by determination of the peak area that corresponded to the retention time (16.3 min) for the analytical spinosad (purity $98 \%$, Spinosyn A and Spinosyn D; Chemservice, West Chester, PA) at $230 \mathrm{~nm}$, using a calibration plot from $0.25-2 \mathrm{mg} \mathrm{mL}^{-1}$ of analytical compound. Fractions were eluted with a methanol + acetonitrile + water solvent mix, starting with a calibration ratio of $2: 2: 96$. Next, 
the following steps were performed: step 1, a linear gradient of

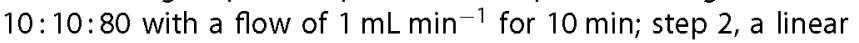
gradient of $25: 25: 50$ with a flow of $1 \mathrm{~mL} \mathrm{~min}^{-1}$ for 2 min; step 3, a linear gradient of $20: 60: 20$ with a flow of $1 \mathrm{~mL} \mathrm{~min}^{-1}$ for $6 \mathrm{~min}$; step 4, an equilibrium phase of $2: 2: 96$ with a flow of $1 \mathrm{~mL} \mathrm{~min}^{-1}$ for $5 \mathrm{~min}$. According to the calibration curve, this quantification procedure resulted in a correlation coefficient $R^{2}=0.99$. Spinosad residues were analysed in triplicate after $0,10,30,40$ and 50 days for $60 \mathrm{mg} \mathrm{L}^{-1}$ and after $0,20,40$ and 50 days for $120 \mathrm{mg} \mathrm{L}^{-1}$. The spinosad residues are expressed on a fresh weight basis $\left(\mu \mathrm{g} \mathrm{g}^{-1}\right)$.

\subsection{Residual activity}

The activity of spinosad residues was determined on newly moulted $(<6 \mathrm{~h}$ old) third instars of $\mathrm{S}$. exigua, which were fed pepper leaves that were collected at the same times as mentioned above $(0,3,5,10,20,30,40$ and 50 days after application). After feeding with artificial diet, third instars were starved for $5 \mathrm{~h}$ before the bioassay to induce a higher feeding rate. A previous study showed that shifting from artificial diet to leaves did not induce any mortality in Spodoptera littoralis Boiduval. ${ }^{24}$

For each time and concentration, a single leaf was placed into ventilated plastic petri dishes $(9 \mathrm{~cm}$ diameter $\times 3 \mathrm{~cm}$ high), and ten larvae were placed on the leaf. To delay leaf dehydration, the petiole of each leaf was enveloped with a piece of moist cotton. Moreover, one layer of wetted tissue paper was placed on the bottom of the petri dish, and a few drops of distilled water were added daily to maintain moisture. Each leaf was considered a replicate. Four replicates per treatment were done, except for the control with water and surfactant only, where nine replicates were done.

Leaves were removed $48 \mathrm{~h}$ later, and then surviving larvae were individually placed into $2 \mathrm{~cm}^{2}$ cylindrical wells of 24-well Castor tissue culture plates containing approximately $8 \mathrm{~g}$ of artificial diet. Larval mortality was scored daily for 6 days ( $144 \mathrm{~h}$ ); if no movement was observed, larvae were considered dead. Percentage pupation was assessed for surviving individuals from both concentrations that were bioassayed. Bioassays were conducted under the same environmental conditions as those detailed in Section 2.1.

\subsection{Consumption rate}

The consumption rate of third instars of S. exigua was determined on each leaf from the residual activity bioassay. Images of these leaves were obtained with an HP Scanjet 3770 scanner and segmented using the free software GIMP v.2.6.6 (GNU Image Manipulation Program, http://www.gimp.org) to distinguish between intact and consumed areas. The resulting images were analysed using the program UTHSCSA Image Tool v.3.0. ${ }^{25}$ The consumption rate was expressed as the average percentage of leaf area consumed per surviving larva, taking into account the number of larvae alive at $48 \mathrm{~h}$, as in Wanner et al. ${ }^{26}$

\subsection{Data analysis}

A simple first-order model (exponential decrease) was fitted to degradation kinetics for each spinosad concentration. ${ }^{27}$ The model equation was $M=M_{0} \exp ^{(-k t)}$, where $M$ is the remaining concentration at time $t, M_{0}$ is the initial concentration and $k$ is the relative degradation rate.

The model fitting and estimation of confidence intervals for model parameters were performed with $\mathrm{R}$ software ${ }^{28}$ using the non-linear least squares method. To obtain a more accurate estimation of the parameters, the same model was applied by pooling the data from both concentrations, assuming that only $M_{0}$ changed with application dose while $k$ remained constant. The equations were $M=M_{60} \exp ^{(-k t)}$ and $M=M_{120} \exp ^{(-k t)}$ for 60 and $120 \mathrm{mg} \mathrm{L}^{-1}$ of spinosad respectively, with parameters $M_{60}, M_{120}$ and $k$. The degradation half-life was calculated as $\mathrm{DT}_{50}=\ln (2) / k$.

Data on consumption rate and percentage pupation were subjected to analysis of variance (ANOVA). The analyses were performed using the general linear models procedure, with the least significant difference (LSD) multiple range test $(P<0.05)$ to separate means using SAS. ${ }^{29}$

Larval mortality was analysed by one-way ANOVA followed by LSD mean separation using the Statgraphics graphic software system (STSC Inc., Rockville, MD). In cases where the assumptions of ANOVA were violated, even after transformation to $\arcsin \sqrt{ } x$, a non-parametric Kruskal-Wallis test was applied.

\section{RESULTS}

\subsection{Residue analysis}

The initial concentrations of spinosad in leaf fresh matter were 50 and $100 \mu \mathrm{g} \mathrm{g}^{-1}$ sample, corresponding to a recovery rate of 80 and $86 \%$ after applications of 60 and $120 \mathrm{mg} \mathrm{L}^{-1}$ of spinosad respectively. The degradation concentrations recovered after 50 days decreased to 39 and $72 \mu \mathrm{g} \mathrm{g}^{-1}$ per sample, corresponding to a loss of 22 and $28 \%$ for 60 and $120 \mathrm{mg} \mathrm{L}^{-1}$ respectively (Fig. 1).

When the exponential model was fitted for the kinetics of each concentration of spinosad separately, the estimated value and confidence interval $(P<0.05)$ for its parameters were as
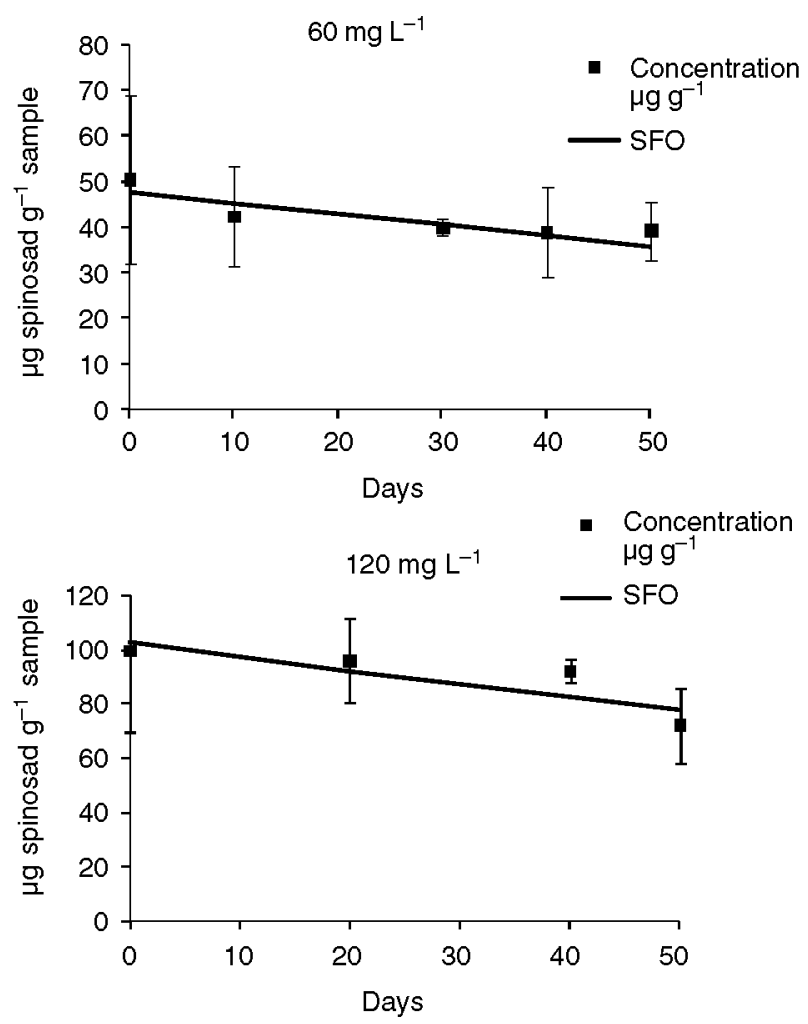

Figure 1. Decline of spinosad residues over time following application to pepper foliage. Data points represent the average residue concentration at different sampling times, and error bars represent the standard deviation. The solid line represents the degradation kinetics, fitted by the simple first-order (SFO) model. 

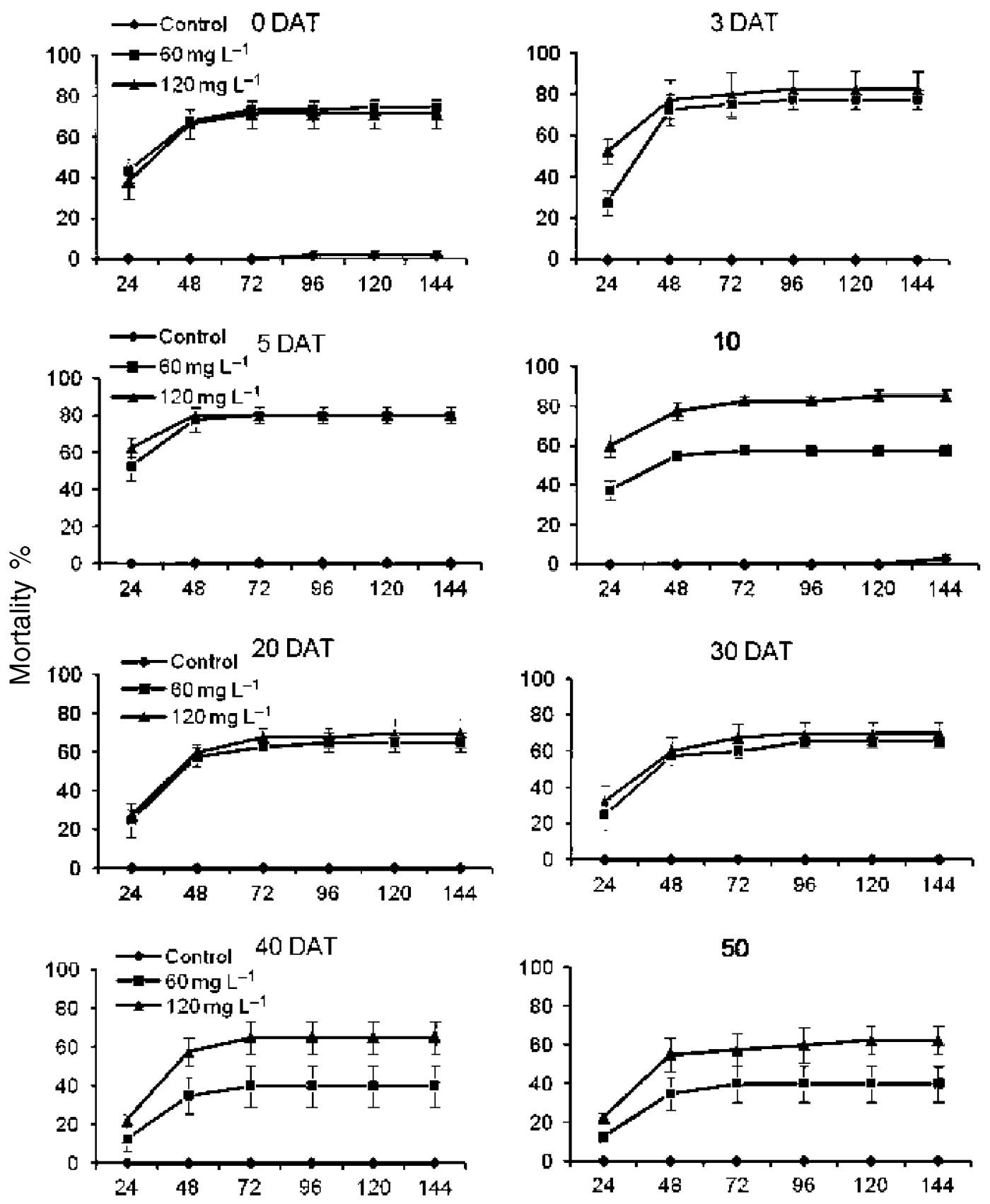

Hours after exposure to treated leaf

Figure 2. Effects of greenhouse-aged leaf residues of spinosad at two different concentrations on third-instar S. exigua (DAT: days after treatment).

follows: for $60 \mathrm{mg} \mathrm{L}^{-1}$ of spinosad, $M_{0}=46.6 \mu \mathrm{g} \mathrm{g}^{-1}$ sample (confidence interval: $36.4<M_{0}<57.3$ ) and $k=4.44 \times 10^{-3}$ (confidence interval: $-3.78 \times 10^{-3}<k<1.32 \times 10^{-2}$ ); for $120 \mathrm{mg} \mathrm{L}^{-1}$ of spinosad, $M_{0}=103.3 \mathrm{\mu g} \mathrm{g}^{-1}$ sample (confidence interval: $79.6<M_{0}<127.7$ ) and $k=5.80 \times 10^{-3}$ (confidence interval: $-1.20 \times 10^{-3}<k<1.23 \times 10^{-2}$ ). In neither case was the degradation rate $k$ significantly different from zero $(P<0.05)$.

When pooling the experiments, $M_{60}=47.7 \mu \mathrm{g} \mathrm{g}^{-1}$ sample (confidence interval: $38.3<M_{60}<57.6$ ), $M_{120}=102.7 \mu \mathrm{g} \mathrm{g}^{-1}$ sample (confidence interval: $87.0<M_{120}<118.9$ ) and $k=$ $5.58 \times 10^{-3}$ (confidence interval: $1.18 \times 10^{-3}<k<9.92 \times 10^{-3}$ ). In this case, $k$ was significantly different from zero $(P<0.05)$. The wide confidence interval around $k$ did not allow estimation of the half-life (estimated value 124 days) with a reasonable precision. However, the lower limit for the confidence interval around half-life was 70 days $(P<0.05)$.

\subsection{Bioassays of residual activity}

Third instars of S. exigua were highly susceptible to spinosad residues. In most of the samples that were bioassayed, an increase was observed in the mortality of third instars of S. exigua up to 72 or $96 \mathrm{~h}$ after the bioassay was started (Fig. 2). Mortality that was caused by 60 and $120 \mathrm{mg} \mathrm{L}^{-1}$ of spinosad was significantly different ( $P \leq 0.008$ for all cases) from that caused by the controls $(\leq 2.5 \%)$ in all age residues. However, there were no significant 
Table 1. Percentage of pupae (mean $\pm \mathrm{SE}$ ) resulting from surviving third instars of $S$. exigua feeding on untreated pepper foliage and foliage that was treated with spinosad

\begin{tabular}{cccc}
\multirow{2}{*}{$\begin{array}{l}\text { Age of } \\
\text { residue in } \\
\text { leaves }\end{array}$} & Control & \multicolumn{3}{c}{60} & 120 \\
\cline { 2 - 4 } & $96 \pm 8 \mathrm{aA}(48)$ & $20 \pm 6 \mathrm{bA}(21)$ & $23 \pm 7 \mathrm{bA}(18)$ \\
\hline 0 days & $90 \pm 9 \mathrm{aA}(36)$ & $25 \pm 9 \mathrm{bA}(9)$ & $25 \pm 10 \mathrm{bA}(7)$ \\
3 days & $87 \pm 0 \mathrm{aA}(35)$ & $21 \pm 9 \mathrm{bA}(8)$ & $21 \pm 9 \mathrm{bA}(8)$ \\
5 days & $95 \pm 9 \mathrm{aA}(38)$ & $30 \pm 9 \mathrm{bA}(5)$ & $25 \pm 9 \mathrm{bA}(6)$ \\
10 days & $87 \pm 9 \mathrm{aA}(35)$ & $33 \pm 9 \mathrm{bA}(13)$ & $29 \pm 9 \mathrm{bA}(11)$ \\
20 days & $82 \pm 9 \mathrm{aA}(32)$ & $35 \pm 9 \mathrm{bA}(14)$ & $31 \pm 9 \mathrm{bA}(12)$ \\
30 days & $100 \pm 9 \mathrm{aA}(40)$ & $39 \pm 9 \mathrm{bAB}(16)$ & $33 \pm 9 \mathrm{bA}(11)$ \\
40 days & $60 \pm 9 \mathrm{bB}(24)$ & $41 \pm 9 \mathrm{bA}(15)$ \\
50 days & $100 \pm 9 \mathrm{aA}(40)$ & $\left.60 \pm \mathrm{mg} \mathrm{L}^{-1}\right)$ \\
\hline
\end{tabular}

Means within columns (upper-case letters) and within rows (lower-case letters) followed by the same letter are not significantly different $(\mathrm{P}>$ 0.01 ; LSD mean separation). Numbers in parentheses are the surviving larvae that ecdysed in normal pupae.

differences between the two concentrations in $0,3,5,20$ and 30 day residues ( $P>0.05$ for all cases), with the exception of $24 \mathrm{~h}$ in the three-day-old residue ( $F=26.13$; df $=2,9 ; P<0.001$ ) (Fig. 2). The mortality for all of these residues was between 25 and $80 \%$ for the two concentrations. In the ten-day-old residue, significant differences $(P \leq 0.007)$ were observed between mortality caused by the two concentrations of spinosad in the $144 \mathrm{~h}$ during which mortality was scored (Fig. 2). In this case, mortality was between 35 and $50 \%$ and between 55 and $80 \%$ for 60 and $120 \mathrm{mg} \mathrm{L}^{-1}$ respectively.

Finally, a decrease in the bioactivity of spinosad was observed. The mortality of S. exigua larvae was between 10 and $35 \%$ and between 20 and $65 \%$ for 60 and $120 \mathrm{mg} \mathrm{L}^{-1}$, respectively, in residues both 40 and 50 days old (Fig. 2). In each residue, significant differences ( $P \leq 0.01$ for both cases) were observed in mortality between the two concentrations that were bioassayed during the $144 \mathrm{~h}$ in which mortality was scored, with the exception of $72 \mathrm{~h}$ for the residue that was 50 days old.

Pupal formation of S. exigua larvae that survived the spinosad treatment was negatively affected (Table 1). This effect was significant for the age of residue $(F=2.26 ; \mathrm{df}=7,79 ; P=0.03)$ and treatment $(F=131 ; \mathrm{df}=2,79 ; P<0.001)$, but not for the interaction between the age of residue and treatment $(F=0.56 ; \mathrm{df}=14,79 ; P=0.88)$. Pupal formation was between 20 and $60 \%$ and between 21 and $41 \%$ for 60 and $120 \mathrm{mg} \mathrm{L}^{-1}$ of spinosad, respectively, in all ages of leaf residues that were bioassayed. No significant differences were observed between the two concentrations, but they were all significantly lower than the controls, where the pupal formation was between 82 and $100 \%$ in all ages of leaf residues. Also, no significant differences were observed in pupal formation among most ages of leaf residues for each concentration bioassayed, the only exception being the residue that was 50 days old in a concentration of $60 \mathrm{mg} \mathrm{L}^{-1}$.

\subsection{Consumption rate}

The effect of spinosad on the consumption rate of third instars of S. exigua exposed for $48 \mathrm{~h}$ to spinosad residues of different ages that were present in pepper foliage is presented in Table 2 . The effect of the treatment was highly significant $(F=149.83$; $\mathrm{df}=2$, $76 ; P<0.001)$. No significant effect of the age of residue $(F=1.70$;
Table 2. Percentage of leaf consumed per surviving larvae (mean \pm SE) by S. exigua third instars feeding on untreated pepper foliage and foliage that was treated with spinosad

\begin{tabular}{clcc}
\multirow{2}{*}{$\begin{array}{l}\text { Age of } \\
\text { residue in } \\
\text { leaves }\end{array}$} & \multicolumn{3}{c}{ Concentration $\left(\mathrm{mg} \mathrm{L}^{-1}\right)$} \\
\cline { 2 - 4 } & \multicolumn{1}{c}{60} & 120 \\
\hline 0 days & $1.7 \pm 0.1 \mathrm{aA}$ & $0.4 \pm 0.1 \mathrm{bA}(75)$ & $0.27 \pm 0.1 \mathrm{bA}(84)$ \\
3 days & $1.6 \pm 0.1 \mathrm{aAB}$ & $0.6 \pm 0.1 \mathrm{bA}(64)$ & $0.53 \pm 0.1 \mathrm{bAB}(67)$ \\
5 days & $1.6 \pm 0.1 \mathrm{aAB}$ & $0.6 \pm 0.1 \mathrm{bA}(63)$ & $0.44 \pm 0.1 \mathrm{bAB}(72)$ \\
10 days & $1.2 \pm 0.1 \mathrm{aB}$ & $0.4 \pm 0.1 \mathrm{bA}(67)$ & $0.55 \pm 0.1 \mathrm{bAB}(54)$ \\
20 days & $1.9 \pm 0.1 \mathrm{aA}$ & $0.5 \pm 0.1 \mathrm{bA}(75)$ & $0.5 \pm 0.1 \mathrm{bAB}(75)$ \\
30 days & $1.6 \pm 0.2 \mathrm{aAC}$ & $0.6 \pm 0.1 \mathrm{bA}(62)$ & $0.5 \pm 0.1 \mathrm{bAB}(68)$ \\
40 days & $1.9 \pm 0.1 \mathrm{aAD}$ & $0.6 \pm 0.1 \mathrm{bA}(70)$ & $0.7 \pm 0.1 \mathrm{bB}(60)$ \\
50 days & $1.2 \pm 0.1 \mathrm{aB}$ & $0.6 \pm 0.2 \mathrm{bA}(70)$ & $0.6 \pm 0.1 \mathrm{bAB}(69)$ \\
\hline
\end{tabular}

Means within columns (upper-case letters) and within rows (lower-case letters) followed by the same letter are not significantly different $(\mathbf{P}>$ 0.01 ; LSD mean separation). Data are the means \pm SE of a minimum of four and a maximum of nine replicates, each consisting of one pepper leaf per residue and concentration. Numbers in parentheses are the percentages of the corresponding consumption rate decrease.

$\mathrm{df}=7,76 ; P=0.13$ ) was observed, nor of the interaction between the age of residue and treatment $(F=1.56$; df $=14,76 ; P=0.11)$. In all ages of residue $(0,3,5,10,20,30,40$ and 50 days old) and in both concentrations that were bioassayed ( 60 and $\left.120 \mathrm{mg} \mathrm{L}^{-1}\right)$, the consumption rate per larva was $<1 \%$, while the control larvae consumed between 1.2 and $1.9 \%$ of treated foliage.

\section{DISCUSSION}

It is well known that leaf age and environmental conditions influence the persistence, and consequently the efficacy, of any chemical insecticide. ${ }^{30,31}$ In particular, photolysis is the main responsible factor of a rapid breakdown of spinosad in the environment. ${ }^{13}$ In the dark, spinosad residues can persist for long periods of time. In wheat grains, degradation was only $37 \%,{ }^{23}$ $42 \%^{32}$ and $44 \%{ }^{33}$ after $6,7.5$ and 9 months storage respectively. In contrast, in studies done under field conditions, where high levels of UV and visible radiation are expected from direct exposure to sunlight, a much faster degradation is reported. According to Saunders and Bret, ${ }^{34}$ the half-life of spinosad in conditions of leaf surface photolysis is $1.6-16$ days. This value is in agreement, for example, with decreases in spinosad residues of $92.3 \%$ (in kiwi fruit leaves) ${ }^{35}$ and up to $97 \%$ (in cabbage, cauliflower and okra leaves) ${ }^{19,20}$ that were observed 55 days and 10 days after treatment respectively. Here, it was found that less than $30 \%$ of spinosad initially present on leaves was degraded after 50 days, which corresponded to a half-life longer than 2 months. This is in contrast to the results of a greenhouse study done by AlMohaimeed $^{36}$ who found 48 and $85 \%$ spinosad degradation on green peppers and tomatoes, respectively, at only 7 days after application. However, these results are not directly comparable with the present findings, because neither temperatures nor the amount of UV light inside the greenhouse were recorded, and they were probably very different. In the present study, the greenhouse intercepted about $75 \%$ of UV radiation, and consequently a much smaller reduction in degradation was found.

In the present study, the mortality of third instars of S. exigua decreased from 80 to $40 \%$ and from 85 to $62 \%$ for 60 and $120 \mathrm{mg} \mathrm{L}^{-1}$ of spinosad, respectively, in all ages of leaf residues 
that were bioassayed. These results are similar to those that were obtained by Liu et al., ${ }^{37}$ who reported that the mortality decreased from 100 to $23 \%$ and from 100 to $85 \%$ in second and third instars of Trichoplusiani (Hübner), respectively, when these were exposed to cabbage leaves (Brassica oleracea L.) with a field-aged leaf residue of 12 days after application. In another study, the mortality caused by spinosad residues that were present in eggplant leaves (Solanum melongena L.) also appeared to be age dependent for adults of Epitrix fuscula Crotch. ${ }^{38}$ This decrease in activity could be explained, as it was in this study, by the degradation of spinosad over time. On the other hand, spinosad residues that were 1.2 and 12 months old in cabbage leaves kept under laboratory conditions or in stored wheat (Triticum sp.) caused $100 \%$ mortality in third instars of $T . n i^{37}$ and in adults of both the lesser grain borer, Rhyzoperta dominica (F.), and the red flour beetle, Tribolium castaneum (Herst). ${ }^{23,32,33}$ This high mortality, caused by residues even after long storage times, was a result of the high persistence of the compound (up to $70 \%$ ) because these cabbage leaves and wheat grains were not exposed to sunlight.

The extended chemical persistence and activity of spinosad on pepper foliage could have a significant impact on several aspects of integrated pest management of this crop. Based on a single greenhouse study, spinosad residues may provide up to $80 \%$ control of lab-reared, insecticide-susceptible $S$. exigua under greenhouse conditions. Additional sublethal effects, including reductions in fecundity and fertility similar to those reported for S. littoralis, ${ }^{24}$ Plutella xylostella (L.) ${ }^{39}$ and Heliothis virescens Fabricius, ${ }^{40}$ may continue to affect larvae and adults for long periods and may impact upon populations in following generations of beet armyworm.

Previous studies demonstrated that spinosad might cause several sublethal effects in subsequent instars of the treated insects. In this study, pupal formation of $S$. exigua larvae that survived the spinosad treatment was reduced by $40-80 \%$ and by $59-79 \%$ for 60 and $120 \mathrm{mg} \mathrm{L}^{-1}$ of spinosad, respectively, in all ages of leaf residues that were bioassayed. Similarly, a reduction of 31 and $53 \%$ in pupal formation was observed in P. xyllostella $a^{41}$ and cotton bollworm, Helicoverpa armigera (Hübner), ${ }^{42}$ when third and second instars were treated with 0.28 and $0.35 \mathrm{mg} \mathrm{L}^{-1}$ of spinosad respectively. It is clear that the effect of this compound reported here was due to its long persistence on pepper leaves and slow degradation through time. Therefore, the spinosad amounts ingested by $S$. exigua larvae were sufficient to be accumulated and to persist within the insect body during development up to the pupae stage and cause the very long-term effect observed. On the other hand, although adult emergence size from both concentrations bioassayed was not measured, this developmental stage was visually smaller than the control. This finding could have practical implications because these individuals could oviposit fewer eggs than untreated individuals, which would consequently affect the population density of the next generation, as reported for P. xylostella $a^{39}$ and H. armigera. ${ }^{40,42}$

In addition, in the present study, surviving larvae from both spinosad concentrations ( 60 and $120 \mathrm{mg} \mathrm{L}^{-1}$ ) were smaller (early fourth instars) compared with control larvae (early fifth instars), which resulted in lower final pupal weights. Here, the authors observed a 10-18\% weight gain suppression in pupae derived from S. exigua larvae that were fed with all residues and both concentrations mentioned (Pineda S, unpublished data). This result is similar to the reduction in weight $(11-13 \%)$ that was observed in $H$. armigera pupae derived from second and fourth instars treated with spinosad. ${ }^{40,42}$ The reason for this reduction is not immediately apparent, but it can be speculated that it is directly related to the mode of action of spinosad. Neurotoxic insecticides cause paralysis of insects ${ }^{43}$ and, consequently, a cessation of feeding. As in the present study, a decrease in the consumption rate has been previously reported in S. exigua, ${ }^{44}$ S. littoralis ${ }^{45}$ and the obliquebanded leafroller, Choristoneura rosaceana (Harris), ${ }^{21}$ after treatment with compounds that belong to the spynosyn family.

In addition to mortality, the two concentrations of spinosad that were bioassayed decreased the consumption rate of thirdinstar S. exigua larvae in a similar manner (between 60 and $84 \%$ ) in every residue age; the sole exception was the ten-day-old residues, which led to a reduction of $54 \%$ in the concentration of $120 \mathrm{mg} \mathrm{L}^{-1}$. Similarly, spinosad caused a reduction of up to $98 \%$ in the consumption rate of third and fifth instars of this same species $^{44}$ and second instars of gypsy moth, Lymantria dispar L., ${ }^{46}$ that were fed leaf discs of lettuce (Lactuca sativa L.) and red oak (Querqus rubra L.) respectively. In another study, 66-dayold residues of spinetoram, a compound of the same family of spynosyns as spinosad, reduced the consumption rate of neonates of C. rosaceana by 40 and $77 \%$ when it was applied to apple trees at half the MFRC and MFRC respectively. ${ }^{21}$ This effect is very important from a practical point of view because larval feeding damage to crops would be lessened, as reported by McLeod et al. ${ }^{38}$ with E. fuscula adults in eggplants that were treated with spinosad.

It is important to point out that it is difficult to extrapolate the results found in this study on the effects of spinosad residues on $S$. exigua larvae to real-world situations. The study was done with a lab population mass reared formany generations without contact with pesticides under controlled environmental conditions. In the field, however, changes at the microhabitat level and fluctuations in the environmental conditions or in the level of pesticide susceptibility in the population may have an influence on its mobility, feeding behaviour and susceptibility towards pesticides.

In conclusion, the results obtained in this study have demonstrated that the degradation of spinosad is slow under actual greenhouse conditions, and that its residues cause lethal and sublethal effects on S. exigua larvae. This indicates that the combination of both effects could have important implications for the population dynamics of the beet armyworm, contributing to its control. On the other hand, it is clear that the persistence of spinosad makes resistance management an important component of its use. Long-term, low-level selection by persistent materials is particularly conducive to resistance development, and care must be exercised to monitor tolerance levels in the field. ${ }^{47}$ Resistance monitoring is always an important component of integrated pest management in vegetable crops, and it may be even more important in this context, where a persistent material exerts selective pressure over an extended period of time. ${ }^{31}$ Therefore, if spinosad use is combined with other methods, such as mating disruption pheromones and biological and cultural control practices, it is possible to avoid resistance development in this pest; consequently, growers could use this compound for several years in an integrated management programme. Finally, the present findings suggest the need for further research to determine the factors that can accelerate the rate of disappearance after the 50 day period.

\section{ACKNOWLEDGEMENTS}

This work was financially supported by the International Foundation for Science, Stockholm, Sweden (IFS Research Grant C/3699-2), and by the Coordinación de la Investigación Científica, Universidad 
Michoacana de San Nicolás de Hidalgo, through a grant to Samuel Pineda. This research forms part of the undergraduate theses of Erika-Liliana Sántis and Luis-Antonio Hernández. The authors are grateful to American Journal Experts for reviewing the English in this paper, which has helped to improve the manuscript.

\section{REFERENCES}

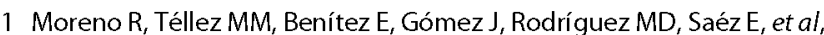
Lucha integrada: aplicación en los cultivos bajo plástico del sur de España. Horticultura 1:41-54 (1992).

2 Smagghe G, Pineda S, Carton B, Del Estal P, Budia F and Viñuela E, Toxicity and kinetics of methoxyfenozide in greenhouse-selected Spodoptera exigua (Lepidoptera: Noctuidae). Pest Manag Sci 59:1203-1209 (2003).

3 Lasa R, Pagola I, Ibañez I, Belda JE, Williams T and Caballero P, Efficacy of Spodoptera exigua multiple nucleopolyhedrovirus as a biological insecticide for beet armyworm control in greenhouses of southern Spain. Biocontrol SciTechnol 17:221-232 (2007).

4 Hill DS, Agricultural Insect Pests of Temperate Regions and their Control. Cambridge University Press, Cambridge, UK (1987).

5 Crop Protection Compendium CD. Global Module, 2nd edition. CAB International, Wallingford, Oxon, UK (2000).

6 Moulton K, Pepper A, Jansson K and Dennehy J, Pro-active management of beet armyworm (Lepidoptera: Noctuidae) resistance to the tebufenozide and methoxyfenozide: baseline monitoring, risk assessment, and isolation of resistance. $J$ Econ Entomol 95:414-424 (2002).

7 Moulton JK, Pepper AD and Dennehy TJ, Beet armyworm (Spodoptera exigua) resistance to spinosad. Pest Manag Sci 56:842-848 (2000).

8 Osorio A, Martínez AM, Schneider MI, Díaz O, Corrales JL, Avilés MC, et al, Monitoring of beet armyworm resistance to spinosad and methoxyfenozide in Mexico. Pest Manag Sci 64:1001-1007 (2008).

9 Thompson DG, Harris BJ, Buscarini TM and Chartrand DT, Fate of spinosad in litter and soils of a white spruce plantation in central Ontario. PestManag Sci 58:397-404 (2002).

10 Sparks C, Thompson D, Kirst A, Hertlein B, Larson L, Worden V, et al, Biological activity of spinosyns, new fermentation derived insect control agents, on tobacco budworm (Lepidoptera: Noctuidae) larvae. J Econ Entomol 91:1277-1283 (1998).

11 Salgado $\mathrm{L}$, The modes of action of spinosad and other insect control products. Down to Earth 52:35-43 (1997).

12 Watson GB, Actions of insecticidal spinosyns on $\gamma$-aminobutyric acid receptors from small-diameter cockroach neurones. Pestic Biochem Physiol 71:20-28 (2001).

13 Thompson GD, Dutton R and Sparks TC, Spinosad - a case study: an example from a natural products discovery programme. PestManag Sci 56:696-702 (2000).

14 Williams T, Cisneros J, Penagos DI, Valle J and Tamez-Guerra P, Ultralow rates of spinosad in phagostimulant granules provide control of Spodoptera friguperda (Lepidoptera: Noctuidae) in maize. JEcon Entomol 2:422-428 (2004).

15 Williams $T$, Valle $J$ and Viñuela $E$, Is the naturally-derived insecticide spinosad compatible with insect natural enemies? Biocontrol Sci Technol 13:459-475 (2003).

16 Schneider MI, Smagghe G, PinedaS and ViñuelaE, Studies on ecological impact of four IGR insecticides in adults of Hyposoter didymator (Hym., Ichneumonidae). Pharmacokinetics approach. Ecotoxicology 17:181-188 (2008).

17 Commission regulation (EC) No. 404/2008 of 6 May 2008 amending Annex II to council regulation (EEC) No. 2092/91 on organic production of agricultural products as concerns the authorisation of spinosad, potassium bicarbonate and copper octanoate and the use of ethylene. Off J Eur Union L120:8 - 10 (2008).

18 Moe SJ, Stenseth NC and Smith RH, Effects of a toxicant on population growth rates: sublethal and delayed responses in blowfly populations. Funct Ecol 15:712-721 (2001).

19 Azab MM, Field persistence of some insecticides on okra leaves as determined by cotton leafworm (Spodoptera littorals) bioassay. JPest Cont Environ Sci 14:43-57 (2006).

20 Sharma A, Srivastava A, Ram B and Srivastava PC, Dissipation behavior of spinosad insecticide in soil, cabbage and cauliflower under sub-tropical conditions. J Agric Food Chem 7:2611-2617 (2008).
21 Sial AA and Brunner JF, Toxicity and residual efficacy of chlorantraniliprole, spinetoram, and emamectin benzoate to obliquebanded leafroller (Lepidoptera: Tortricidae). J Econ Entomol 103:1277-1285 (2010).

22 McKinlay AF and Diffey BL, A reference spectrum for ultravioletinduced erythema in human skin, in Human Exposure to Ultraviolet Radiation: Risks and Regulations, ed. by Passchier WF and Bosnajakovic BF. Elsevier Science, London, UK, pp. 83-87 (1987).

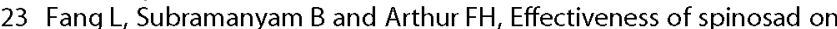
four classes of wheat against five stored-product insects. J Econ Entomol 95:640-650 (2002).

24 Pineda S, Schneider MI, Smagghe G, Martínez AM, Del Estal P, Viñuela $E$, et al, Lethal and sublethal effects of methoxyfenozide and spinosad on Spodoptera littoralis (Lepidoptera: Noctuidae). J Econ Entomol 100:773-780 (2007).

25 Wilcox CD, Brent S, Dove W, McDavid D and Greer DB, Image Tool Version 3.0. University of Texas Health Science Center, San Antonio, TX (2002).

26 Wanner KW, Helson BV and Harris BJ, Laboratory and field evaluation of spinosad against the gypsy moth, Lymantria dispar. Pest Manag Sci 56:855-860 (2000).

27 Boesten JJTI, Aden K, Beigel C, Beulke S, Dust M, Dyson JS, et al, The final report of the work group on degradation kinetics of FOCUS (forum for the coordination of pesticide fate models and their use). Guidance document on estimating persistence and degradation kinetics from environmental fate studies on pesticides in $\mathrm{EU}$ registration. Sanco/10058/2005, v.2.0, June (2006)

28 R: A Language and Environment for Statistical Computing. [Online]. $\mathrm{R}$ Development Core Team, R Foundation for Statistical Computing, Vienna, Austria (2010). Available:http://www.R-project.org [8March 2011].

29 SAS/STAT User's Guide, Version 9.1. SAS Institute, Cary, NC (2002).

30 Pons $\mathrm{S}$, Avilla J and Riedl $\mathrm{H}$, Efecto del momento de aplicación y volumen de tratamiento en la efectividad de tebufenocida para el control de Cydia pomonella (L.) (Lepidoptera: Tortricidae). Bol San Veg Plagas 24:921-934 (1998).

31 Smirle MJ, Lowery DT and Zurowski CL, Chemical residues and bioactivity of tebufenozide applied to apple foliage. Pest Manag Sci 60:1137-1142 (2004)

32 Daglish GJ, Head MB and Hughes PB, Field evaluation of spinosad as a grain protectant for stored wheat in Australia: efficacy against Rhyzopertha dominica (F.) and a fate of residues in whole wheat and milling fractions. Aust J Entomo/ 47:70-74 (2008).

33 Daglish GJ and Nayak MK, Long-term persistence and efficacy of spinosad against Rhyzopertha dominica (Coleoptera: Bostrychidae) in wheat. Pest Manag Sci 62:148-152 (2006).

34 Saunders DG and Bret BL, Fate of spinosad in the environment. Down to Earth 52:14-20 (1997).

35 Tomkins AR, Holland PT, Thomson C, Wilson DJ and Malcolm CP, Residual life of spinosad on kiwifruit-biological and chemical studies. Proc 52nd New Zealand Plant Protection Conf, Auckland, New Zealand, pp. 94-97 (1999).

36 Al-Mohaimeed SAA, Determination of Some Insecticide Residues on Green Pepper and Tomatoes and the Effect of Cooking and Cooling on these Residues. [Online]. Plant Protection Department, College of Food and Agricultural Science, King Saud University, Riyadh (2004). Available: http://colleges.ksu.edu.sa/ FoodsAndAgriculture/PlantProtection/Pages/MSThesisEnglish. aspx [14 October 2011].

37 Liu T, Sparks AN, Jr, Hendrix WH, III, and Yue B, Effects of SpinTor (spinosad) on cabbage looper (Lepidoptera: Noctuidae): toxicity and persistence of leaf residue on cabbage under field and laboratory conditions. J Econ Entomol 92:1266-1273 (1999).

38 McLeod P, Diaz FJ and Johnson DT, Toxicity, persistence, and efficacy of spinosad, chlorfenapyr, and thiamethoxam on eggplant when applied against the eggplant flea beetle (Coleoptera: Chrysomelidae). J Econ Entomol 95:331-335 (2002).

39 Sayyed AH, Saeed S, UI-Ane N and Crickmore N, Genetic, biochemical, and physiological characterization of spinosad resistance in Plutella xylostella (Lepidoptera: Plutellidae).J Econ Entomol 101:1658-1666 (2008).

40 Wang $\mathrm{D}$, Qiu $\mathrm{X}$, Wang $\mathrm{H}$, Qiao $\mathrm{K}$ and Wang $\mathrm{K}$, Reduced fitness associated with spinosad resistance in Helicoverpa armigera. Phytoparasitica 38:103-110(2010). 
41 Yin HY, Wu QJ, Li XF, Zhang YJ and Xu BY, Sublethal effects of spinosad on Plutella xyllostella (Lepidoptera: Yponomeutidae). Crop Prot 27:1385-1391 (2008).

42 Wang D, Gong P, Li M, Qiua X and Wang K, Sublethal effects of spinosad on survival, growth and reproduction of Helicoverpa armigera (Lepidoptera: Noctuidae). Pest Manag Sci 65:223-227 (2008).

43 Haynes KF, Sublethal effects of neurotoxic insecticides on insect behavior. Annu Rev Entomol 33:149-168 (1988).

44 Yee WL and Toscano NC, Laboratory evaluations of synthetic and natural insecticides on beet armyworm (Lepidoptera: Noctuidae) damage and survival on lettuce. J Econ Entomo/ 91:56-63 (1998).
45 Pineda S, SmaggheG, Schneider MI, Del Estal P, Viñuela $\mathrm{E}$, Martínez AM, et al, Toxicity and pharmacokinetics of spinosad and methoxyfenozide to Spodoptera littoralis (Lepidoptera: Noctuidae). Environ Entomol 35:856-864 (2006).

46 Wanner KW, Helson BV and Harris BJ, Laboratory and field evaluation of spinosad against the gypsy moth, Lymantria dispar. Pest Manag Sci 56:855-860 (2000)

47 Taylor CE and Georghiou GP, Influence of pesticides persistence in evolution of resistance. Environ Entomol 11:746-750 (1982). 